\title{
Epidemiological and clinical aspects of a sample of Brazilian patients with primary dystonia and the impact of the new classification on their clinical evaluation
}

\author{
Aspectos epidemiológicos e clínicos de uma amostra de pacientes brasileiros com \\ distonia primária e impacto da nova classificação em sua avaliação clínica \\ Torben Cavalcante Bezerra', Nathália Novaretti², Ana Luiza Nunes Cunha², Márcio Alexandre Pena Pereira², \\ Daniel Sabino de Oliveira², Manuelina Capelari Marcuz Brito², Ângela Vieira Pimentel², Vitor Tumas²
}

\begin{abstract}
Dystonia is a relatively common movement disorder but some of its epidemiological and clinical aspects have not been well characterized in Brazilian patients. Also, a new clinical classification for the disorder has been proposed and its impact on clinical practice is unclear. We aimed to describe the clinical and demographic characteristics of a Brazilian series of patients with primary dystonia, to estimate its local prevalence, and to explore the impact of using a new classification for dystonia. We identified 289 patients with primary dystonia over a 12-month period, of whom 235 underwent a detailed evaluation. Patients with primary dystoniamade up one-sixth of all patients evaluated at the service where the study was conducted, with an estimated local prevalence of 19.8/100,000 inhabitants. The clinical and demographic characteristics of the patients were similar to those described elsewhere, with blepharospasm as the most common focal dystonia and most patients using sensory tricks that they judged useful on a day-to-day basis. The application of the new classification was easy and simple, and the systematic approach allowed for a better clinical characterization of our patients. We recognized two dystonic syndromes that were not described in the original article that proposed the classification, and suspected that the arbitrary distinction between generalized and multifocal dystonia seems not to be useful for patients with primary dystonia.In conclusion, the prevalence and clinical characteristics of our patients were not distinct from other studies and the new classification was shown to be practical and useful to characterize patients with dystonia.
\end{abstract}

Keywords: Dystonic disorder; diagnosis; prevalence.

RESUMO

A distonia é um distúrbio de movimento relativamente comum e alguns de seus aspectos epidemiológicos e clínicos ainda não foram bem caracterizados em pacientes brasileiros. Além disso, uma nova classificação clínica para o transtorno foi proposta e seu impacto na prática clínica não é claro. Nosso objetivo é descrever as características clínicas e demográficas de uma série brasileira de pacientes com distonia primária, estimar sua prevalência local e explorar o impacto do uso de uma nova classificação para distonia. Foram identificados 289 pacientes com distonia primária (PDYS) durante um período de 12 meses, dos quais 235 foram submetidos a uma avaliação detalhada. Os pacientes com PDYS corresponderam a um sexto de todos os pacientes avaliados no serviço em que o estudo foi realizado, com uma prevalência local estimada de 19,8/100.000 habitantes. As características clínicas e demográficas dos pacientes foram semelhantes àquelas descritas em outros locais, com o blefaroespasmo como distonia focal mais comum e a maioria dos pacientes apresentando truques sensoriais que julgaram úteis no dia-a-dia. A aplicação da nova classificação foi fácil e simples, e a abordagem sistemática permitiu uma melhor caracterização clínica de nossos pacientes. Reconhecemos duas síndromes distônicas que não foram descritas no artigo original que propôs a classificação e suspeitamos que a distinção arbitrária entre distonia generalizada e multifocal parece não ser útil para pacientes com PDYS. Em conclusão, a prevalência e as características clínicas de nossos pacientes não foram distintas de outras amostras e a nova classificação mostrou-se prática e útil para caracterizar pacientes com distonia.

Palavras-chave: Distúrbios distônicos, diagnóstico; prevalência.

'Universidade Federal do Amazonas, Faculdade de Medicina, Departamento de Cirurgia, Manaus AM, Brasil;

${ }^{2}$ Universidade de São Paulo, Faculdade de Medicina de Ribeirão Preto, Departamento de Neurociência e Ciências do Comportamento, São Paulo SP, Brasil. Correspondence: Vitor Tumas; Departmento de Neurociências e Ciências do Comportamento, Faculdade de Medicina de Ribeirão Preto da Universidade de São Paulo; Av dos Bandeirantes, 3900, Campus Universitário;14049-900Ribeirão Preto SP, Brasil. E-mail: tumasv@fmrp.usp.br

Conflict of interest: There is no conflict of interest to declare.

Received 09 May 2018; Received in final form 20 September 2018; Accepted 24 September 2018 
Dystonia is a term used today to describe characteristic abnormal movements and to name specific clinical syndromes ${ }^{1}$. It was in the 1970s that authors characterized dystonia and, over time, the concept and classification of dystonia has evolved ${ }^{2,3}$. In 1987,Fahn, Marsden, and Calne proposed a classification for dystonia based on the age at onset, body distribution of movements, and possible etiology ${ }^{4}$. Later, in 1998,Fahn, Bressman, and Marsden expanded the etiological classification of dystonia and defined four main categories: primary, dystonia-plus, secondary, and heredodegenerative dystonias ${ }^{5}$. Those authors defined primary dystonias as syndromes in which dystonia was the sole motor phenotypic manifestation with the exception of tremor. Dystoniaplus referred to syndromes that presented with other associated neurological features (parkinsonism or myoclonus), but which could not be classified as neurodegenerative diseases.

More recently, a task force of the International Parkinson and Movement Disorders Society (MDS) proposed a new clinical classification for dystonia ${ }^{1}$. The new classification characterizes dystonia along two main axes. The first axis consists of a detailed description of fundamental clinical aspects of the disorder (age at onset, body distribution, temporal pattern, and associated features); whereas the second axis refers to the etiology of dystonia. The clinical classification axes would allow a more accurate determination of the possible etiology of dystonia. Some of the updates in theMDS classification allow a more precise definition of some clinical aspects of dystonia.

The MDS classification summarized the etiological classification of dystonia into hereditary, acquired or idiopathic. Since this new classification reflects advances in knowledge about the phenomenology and etiology of dystonia, it is expected to contribute to a better characterization and management of patients with dystonia. However, to date, the applicability and utility of this new classification have not been well established.

Many studies have described the main clinical features of patients with primary dystonia in different clinical settings, including some Brazilian series ${ }^{6,7,8}$. However, there are no recent studies involving samples large enough to characterize detailed epidemiological and clinical aspects of Brazilian patients with primary dystonia. Even though dystonia is one of the most common movement disorders, there are few available epidemiological data on this subject. A recent systematic review pointed to an overall prevalence of primary dystonia of around 16 cases per 100,000 inhabitants, but the authors suggested that this frequency could have beenunderestimated ${ }^{9}$. The prevalence of secondary dystonia is even less known, but it has been estimated to be less frequent than primary dystonia in one case series ${ }^{6}$.In the absence of reliable epidemiological data, it is important to describe the frequency of the main clinical forms of dystonia in a Brazilian setting and to try to estimate the prevalence of dystonia in the local population.
We aimed to describe the clinical and demographic characteristics of a large case series of Brazilian patients with primary dystonia and dystonia-plus attending a specialized clinic, using the classification proposed by the MDS. We also estimated the local prevalence of primary dystonia.

\section{METHODS}

This was a descriptive, cross-sectional analysis of a series of Brazilian patients with a diagnosis of primary dystonia and dystonia-plus attending a specialized clinic. All patients seen in the Movement Disorders Section Ribeirao Preto School of Medicine Hospital of the University of São Paulo, between March 2015 and February 2016 were included. The service only accepts patients above 17 years of age. The inclusion criterion was a diagnosis of primary dystonia or dystoniaplus according to the classification of Fahn, Bressman, and Marsden ${ }^{5}$. The exclusion criterion was the presence of any other possible cause for dystonia.

A movement disorders specialist evaluated all the patients at some point. At the service where the study was conducted, the diagnostic approach for dystonia is defined on an individual basis considering the age of onset of dystonia, the body distribution of movements, hereditary aspects, temporal aspects of the symptoms, and presence of associated features ${ }^{10}$. For this study, a clinical neurologist (TCB) examined all the patients, reviewed and collected clinical and demographic data, and performed a detailed neurological evaluation that included the application of the BurkeFahn-Marsden scale ${ }^{11}$. After this evaluation, the neurologist defined the suspected etiology of the dystonia. Suspected cases of a secondary origin for dystonia were subjected to a neuroimaging examination and to complementary assessments considered to be important, on an individual basis. For those patients who refused to participate in the complete clinical reevaluation, we reviewed previous clinical data to confirm the diagnosis of primary dystonia. Patients were initially classified according to the Fahn, Bressman, and Marsden classification ${ }^{5}$ and then according to the MDS classification ${ }^{1}$. We did not perform genetic tests for the diagnosis of specific causes of hereditary dystonia in the patients of this study due to the unavailability of this resource in our service.

We estimated the local prevalence of primary dystonia considering that our service is inside a public hospital in the main city of a region with a population of 1,483,715 inhabitants (Brazilian Institute of Geography and Statistics), and is the only public health service to receive patients with movement disorders in this region. We used local data to consider that about $75 \%$ of the patients from our hospital are living in our administrative region, and that about $60 \%$ of the local population depends on the public health service.

The clinical and demographic characteristics of the sample were analyzed with a descriptive analysis. The 
Shapiro-Wilk test was used to determine if the variables of the sample had a normal distribution. Since most of the variables were not normally distributed, we used the KruskalWallis test to compare independent groups and the chisquare test to compare nominal variables.

The Ethics Committee of the University Hospital of the Ribeirao Preto School of Medicine, which applies the principles of the Declaration of Helsinki, approved the study under protocol number 12736/2011. All participants signed an informed consent to participate or allow the use of their clinical data.

\section{RESULTS}

During the 12-month evaluation period, 1,761 patients attended the movement disorders service and the diagnoses of primary dystonia or dystonia-plus was confirmed in 289 patients (16.4\%). Out of this total, detailed data of 54 patients

Table 1. Clinical and demographic characteristics of a sample of 235 patients with primary dystonia* or dystonia-plus* who attended our service over a 12 -month period.

\begin{tabular}{|c|c|}
\hline $\begin{array}{l}\text { Clinical and demographic } \\
\text { characteristics }\end{array}$ & $\mathrm{n}(\%)$ \\
\hline Sex (male / female) & $91 / 144$ \\
\hline Age (years) - (mean $\pm S D)$ & $59.9 \pm 15.8$ \\
\hline Years of education (mean \pm SD) & $7.1 \pm 5.3$ \\
\hline Primary dystonia - n (\%) & $227(97 \%)$ \\
\hline Dystonia-plus - n (\%) & $8(3 \%)$ \\
\hline Dystonia-parkinsonism & 3 \\
\hline Dystonia-myoclonus & 5 \\
\hline Body distribution of dystonia & $n(\%)$ \\
\hline Focal dystonia & $152(64.6 \%)$ \\
\hline Blepharospasm & $60(25.5 \%)$ \\
\hline Cervical dystonia & $51(21.7 \%)$ \\
\hline Limbdystonia** & $28(11.9 \%)$ \\
\hline Laryngealdystonia & $10(4 \%)$ \\
\hline Oromandibulardystonia & $3(1.2 \%)$ \\
\hline Segmental dystonia & $46(19.5 \%)$ \\
\hline Meige's syndrome & $20(8.5 \%)$ \\
\hline Craniocervical dystonia & $13(5.5 \%)$ \\
\hline Limb-axial dystonia & $6(2.5 \%)$ \\
\hline Cranio-laryngo-cervical dystonia & $4(1.7 \%)$ \\
\hline Laryngo-cervical dystonia & $2(0.8 \%)$ \\
\hline Cranio-laryngeal dystonia & $1(0.4 \%)$ \\
\hline Multifocal dystonia & $23(9.7 \%)$ \\
\hline Generalizeddystonia & $14(5.9 \%)$ \\
\hline Total & 235 patients \\
\hline
\end{tabular}

*According to the classification of 1998 Fahn, Bressman, and Marsden ${ }^{5}$; * 25 patients with simple writer's cramp; SD: standard deviation. were not included in the clinical characterization because they refused to participate in the complete clinical evaluation. We therefore used data from 235 patients for the clinical characterization of the sample (Table 1), and of 289 patients to estimate the local prevalence of dystonia.

Primary dystonia was the diagnosis in approximately onesixth of all patients seen at our outpatient clinic during a oneyear period, and we estimated a local prevalence of around 19.8 cases of primary dystonia for every 100,000 inhabitants.

The clinical characterization of the sample showed that focal and segmental dystonia were the most common clinical presentations of primary dystonia (84.1\%) (Table 1). Blepharospasm (25.5\%) was the most common focal dystonia, followed by cervical dystonia $(21.7 \%)$ and limb dystonia. Meige's syndrome and craniocervical dystonia were the most common segmental dystonia presentations. Focal, segmental, and generalized dystonias predominantly affected females, whereas upper limb dystonia, dystoniamyoclonus, and multifocal dystonia affected more males than females $(p<0.05)$.Patients with generalized dystonia, multifocal dystonia, and dystonia-plus had a lower age at onset of dystonia than all the other types of dystonia ( $p$ $=0.0001$ ), while patients with upper limb dystonia had a lower age at onset than the other focal and segmental dystonias $(p=0.0001)$. Seventy-nine patients $(33 \%)$ reported the use of sensory tricks, which were more frequent in patients with cervical dystonia (59\%), but also present in patients with oromandibular dystonia (33\%), blepharospasm (28\%), segmental dystonia (33\%), multifocal dystonia (39\%), and generalized dystonia (14\%). For one-third of the patients, sensory tricks produced a slight alleviation, while for two-thirds the tricks produced moderate or significant relief of the symptoms. Twenty-six patients (33\%) reported that the beneficial effect of sensory tricks persisted for several minutes, while most (66\%) described that the clinical benefit lasted for a short period only. Despite this, 64/79 $(81 \%)$ of the patients classified sensory tricks as useful on a day-to-day basis. Thirty-one (13\%) patients of our sample had a familial history of dystonia. This group was formed by 8 (5\%) out of 152 patients with focal dystonia, 9 (20\%) out of 46 patients with segmental dystonia, 7 (30\%) out of 23 patients with multifocal dystonia, and 7 (50\%) out of 14 patients with generalized dystonia.

When we used the MDS classification of dystonia, two patients previously classified as having generalized dystonia were reclassified with multifocal dystonia. Table 2 shows the classification of patients by age at onset of dystonia according to the Fahn et al. ${ }^{5}$, and MDS classifications ${ }^{1}$. The main change with the use of the MDS classification was the categorization of patients into more age categories than the previous classification. We found that the distribution of patients in these categories completed the full range of groups of age at onset proposed by the MDS classification. Using this new categorization, the proportion of cases of familial dystonia 
Table 2. Classification of 235 patients with idiopathic dystonia according to age at onset of dystonia.

\begin{tabular}{|c|c|c|c|c|}
\hline Variable & Age atonset & $\mathrm{n}$ & $\begin{array}{l}\mathrm{n}(\%) \text { of generalized and } \\
\text { multifocal dystonia }\end{array}$ & $\begin{array}{c}\mathrm{n}(\%) \text { of positive family } \\
\text { history }\end{array}$ \\
\hline \multirow{6}{*}{ MDS classification of dystonia ${ }^{1}$} & $0-2$ years & 3 & $3(100 \%)$ & $2(66 \%)$ \\
\hline & $2-12$ years & 16 & $12(75 \%)$ & $5(31 \%)$ \\
\hline & $13-20$ years & 14 & $9(64 \%)$ & $3(21 \%)$ \\
\hline & $21-40$ years & 38 & $8(21 \%)$ & $10(26 \%)$ \\
\hline & $>40$ years & 164 & $5(3 \%)$ & $11(7 \%)$ \\
\hline & Total & 235 & & \\
\hline \multirow{4}{*}{$\begin{array}{l}\text { Classification of Fahn, Bressman, and } \\
\text { Marsden }{ }^{5}\end{array}$} & $0-12$ years & 19 & $12(79 \%)$ & $7(37 \%)$ \\
\hline & $13-20$ years & 14 & $9(64 \%)$ & $3(21 \%)$ \\
\hline & $>20$ years & 202 & $13(6 \%)$ & $21(10 \%)$ \\
\hline & Total & 235 & & \\
\hline
\end{tabular}

Table 3. Classification of 235 patients with idiopathic dystonia according to the dystonia syndrome as proposed by Albanese et al.1.

\begin{tabular}{lc}
\hline Dystonia syndrome & $\mathrm{n}$ \\
\hline *Early-onset generalized isolated dystonia & 9 \\
\hline Early-onset multifocal isolated dystonia & 13 \\
\hline Early-onset focal or segmental isolated dystonia & 21 \\
$\begin{array}{l}\text { Late-onset generalized or multifocal dystonia } \\
\text { *Focal or segmental isolated dystonia with onset in } \\
\text { adulthood }\end{array}$ & 11 \\
$\begin{array}{l}\text { *Dystonia-parkinsonism } \\
\text { *Myoclonus-dystonia }\end{array}$ & 3 \\
\hline *Dystonic syndrome defined in the publication of the proposed & MDS \\
classification for dystonia. &
\end{tabular}

and generalized and multifocal dystonia reduced gradually as the age at dystonia onset increased.

Considering the temporal pattern of dystonia, all 235 patients reported that the long-term disease course was static at the time of the evaluation. Only 37 (15.7\%) patients described diurnal variability in dystonia, which was due to the action-specific character of task-specific dystonia in 25 patients. Twelve patients reported spontaneous diurnal fluctuation of dystonic movements. Three of them had dystonia-parkinsonism, while four other patients reported diurnal variability in dystonia and showed improvement with the use of levodopa, despite the absence of parkinsonism. Of these, two patients had multifocal dystonia, one had segmental dystonia and one had upper limb dystonia. Five patients, including two with cervical dystonia and three with blepharospasm, reported diurnal fluctuations in their symptoms, but had no clinical benefit with the use of levodopa.

With respect to the presence of associated features, we diagnosed combined dystonia in eight patients (three patients with parkinsonism and five with myoclonus) and isolated dystonia in 227 patients. After this new clinical categorization of patients with primary dystonia, we classified their syndromic patterns in seven subtypes (Table 3). Considering the etiological classification of dystonia, we classified all 235 patients with primary dystonia as having idiopathic dystonia. There were 204 patients with sporadic idiopathic dystonia and 31 patients with familial idiopathic dystonia. Because of the limited information about the affected family members of our patients, we were unable to determine the probable type of genetic transmission for any of those with familial dystonia.

\section{DISCUSSION}

Primary dystonia was the diagnosis of approximately $17 \%$ of all patients seen at our service during a period of one year, confirming the high prevalence of patients with dystonia followed at specialized clinical settings. Using demographic and local data from health services, we estimated a local prevalence rate of around 19.8 cases of primary dystonia for every 100,000 inhabitants. That was a vague estimate; however, it suggests that the frequency of primary dystonia in Brazil is probably very similar to that observed in other regions of the world ${ }^{9,12}$. Despite the significant limitation of our analysis, to our knowledge, there are no other epidemiological data or estimates of the frequency of primary dystonia in Brazil.

The clinical characteristics of patients in our sample were quite similar to those reported in other studies ${ }^{6,79}$. Focal and segmental dystonia were the most common clinical presentations of primary dystonia. However, in our study, blepharospasm was the most common focal dystonia, and this observation is different from many others that reported cervical dystonia as the most prevalent form of focal dystonia ${ }^{6,9,12}$.

It is believed that the presentation of some clinical forms of dystonia may be determined by genetic and environmental factors. This hypothesis is well illustrated in the effect of repetitive motor practice as a factor associated with the 
clinical expression of writer's or musician's cramps ${ }^{13}$. Also, some authors have suggested that high exposure to sunlight could increase the incidence of blepharospasm ${ }^{12}$. This is an interesting hypothesis to explain our findings, as the exposure to sunlight is very high in our region. However, we cannot rule out the possibility of biases in the referral of patients to our service.

In our sample, primary dystonia affected more females than males in general, except for upper limb dystonia, which predominantly affected men. These findings are similar to those of earlier reports ${ }^{9}$. As expected, generalized dystonia, multifocal dystonia and dystonia-plus had a lower age of onset than other primary dystonias ${ }^{9}$. There were no cases of hemi dystonia in our sample, confirming that this clinical presentation of dystonia is not suggestive of a diagnosis of primary dystonia ${ }^{14}$.

Sensory tricks are a distinct phenomenon of dystonia and may help in the differentiation between dystonia and other abnormal movements ${ }^{1}$. They are defined as voluntary sensory stimulation, usually applied to the body part affected by dystonia, that produces some alleviation of the abnormal movements ${ }^{15}$. One-third of our patients reported the use of sensory tricks, especially patients with cervical dystonia. However, we observed the use of such tricks in all forms of dystonia, as described in the literature ${ }^{16}$. The frequency of use of sensory tricks by our patients with cervical dystonia was of $59 \%$, which is very close to that described in other studies $^{16}$. The tricks reported by our patients were also similar to those described in the literature and produced short but significant clinical benefit for most patients, and most also considered them useful on a day-to-day basis. This observation reinforces the idea that sensory tricks should be explored as a complementary treatment for patients with dystonia ${ }^{15}$.

As previously suggested, the MDS classification seems to be an easy-to-use procedure for classifying patients with dystonia, and we did not observe any practical obstacles to its application ${ }^{17,18}$. There were no significant changes in the characterization of patients according to the distribution of dystonia in the body, except for the new definition of generalized and multifocal dystonia. The MDS classification brings different guidelines for the definition of generalized dystonia, changing the requirement of involvement of one or both legs to the requirement of involvement of the trunk and at least two other body sites. These changes led to the reclassification of only two patients in our sample. The MDS classification of generalized dystonia is intended to be less strictly associated with some specific forms of genetic dystonia characterized by the onset of symptoms in the lower limbs. In our sample, the practical impact of this change was negligible. These findings suggest that the changes proposed for the definition of multifocal and generalized dystonia may have little impact in clinical practice, and that the usefulness of these new definitions still need to be determined.
The MDS classification defines five distinct categories of age at dystonia onset instead of the three categories available in the previous classifications. The authors established these categories to maintain consistency with similar classifications used for other neurological disorders. These changes could help in improving the determination of diagnostic tests and definition of dystonia prognoses. We observed that the patients in our sample were distributed over all five categories, which suggests that the proposed categorization encompasses all intervals of age at the onset of symptoms of patients with primary dystonia. The known relationships between age at onset of dystonia and body distribution of movements or frequency of positive family history of dystonia were evident in our sample using the MDS classification. While apparently rational and useful, the practical relevance of this new categorization could not be tested in our study.

The MDS classification includes relevant clinical aspects that need to be described for each patient, such as the temporal pattern of disease onset and course, the daily variability of symptoms, and the presence of associated features. These clinical aspects have been recognized as important clinical clues for the diagnosis of some forms of dystonia; however, they have not been systematically described for all cases. The importance of some of these clinical aspects was suggested by the analysis of data from our patients regarding the presence of diurnal fluctuations in dystonia. As described, some of our patients had daily fluctuations in their symptoms and a positive response to the use of levodopa, but in the absence of the classical phenotype that characterizes dopa-responsive dystonia. These patients may suffer from uncommon clinical presentations of this syndrome. On the other hand, some patients with typical late-onset focal dystonia also referred to some diurnal fluctuation in their symptoms, but the relevance of this observation remains to be determined.

The requirement for the characterization of dystonic syndromes in the MDS classification led to the definition of seven distinct dystonic syndromes in our sample. These included the four clinical syndromes previously defined by the authors of the MDS classification (Table 3) and three additional syndromes defined in our sample: early-onset multifocal isolated dystonia, early-onset focal or segmental isolated dystonia, and late-onset generalized or multifocal dystonia. We believe that the syndrome of early-onset multifocal isolated dystonia should be considered equivalent to the syndrome of early-onset generalized isolated dystonia. An interesting, but not completely surprising finding, was the recognition of two other syndromes in which the distribution of dystonia sites was unusual for the age at onset of dystonia. The definition of specific dystonic syndromes may be helpful for the etiological diagnosis of dystonia. However, the relevance of the syndromes described in our sample has yet to be determined.

It became clear in our experience with the MDS classification that the proposed process could help structure the 
essential clinical information for the diagnosis of the etiology of dystonia. Larger studies involving an extensive etiological investigation are necessary to determine the usefulness of this approach. In general, as we observed, the MDS classification is easily performed by the clinician, and has the advantage of including many aspects that are essential for the basic characterization of patients with dystonia.

Our study has several limitations, among which we must highlight the absence of genetic tests and the consequent impossibility of assessing the impact of the MDS classification in the determination of the specific genetic etiology of our patients with dystonia. Our analysis of the impact of the MDS classification on the evaluation of patients with primary dystonia is only a partial view of its usefulness. It is possible that this classification may prove to be more important in the future for the characterization of younger patients with dystonia or in cases of acquired dystonias or dystonias with more complex phenotypes.

\section{References}

1. Albanese A, Bhatia K, Bressman SB, Delong MR, Fahn S, Fung VS et al. Phenomenology and classification of dystonia: a consensus update. Mov Disord. 2013 Jun;28(7):86373. https://doi.org/10.1002/mds.25475

2. Fahn S, Eldridge R. Definition of dystonia and classification of the dystonic states. Adv Neurol. 1976;14:1-5.

3. Marsden CD. Dystonia: the spectrum of the disease. Res Publ Assoc Res NervMent Dis. 1976;55:351-67.

4. Fahn S, Marsden CD, Calne DB. Classification and investigation of dystonia. In: Marsden CD, Fahn S, editors. Movement disorders 2. London: Butterworths; 1987. p. 332-58.

5. Fahn S, Bressman SB, Marsden CD. Classification of dystonia. Adv Neurol. 1998;78:1-10.

6. Andrade LA, Ferraz HB. Idiopathic dystonia clinical, profile of 76 Brazilian patients. ArqNeuropsiquiatr. 1992 Dec;50(4):426-32. https://doi.org/10.1590/S0004-282X1992000400003

7. Mattos JP, Rosso AL, Novis S. [Dystonias: clinical and therapeutic aspects in 64 patients]. ArqNeuropsiquiatr. 1996 Mar;54(1):30-6. Portuguese. https://doi.org/10.1590/S0004-282X1996000100005

8. Ferraz HB, Andrade LA. Symptomatic dystonia: clinical profile of 46 Brazilian patients. Can J Neurol Sci. 1992 Nov;19(4):504-7.

9. Steeves TD, Day L, Dykeman J, Jette N, Pringsheim T. The prevalence of primary dystonia: a systematic review and meta-analysis. Mov Disord. 2012 Dec;27(14):1789-96. https://doi.org/10.1002/mds.25244

10. Jinnah HA, Factor SA. Diagnosis and treatment of dystonia. Neurol Clin. 2015 Feb;33(1):77-100. https://doi.org/10.1016/j.ncl.2014.09.002
11. Burke RE, Fahn S, Marsden CD, Bressman SB, Moskowitz C, Friedman J. Validity and reliability of a rating scale for the primary torsion dystonias. Neurology. 1985 Jan;35(1):73-7. https://doi.org/10.1212/WNL.35.1.73

12. Williams L, McGovern E, Kimmich O, Molloy A, Beiser I, Butler JS et al. Epidemiological, clinical and genetic aspects of adult onset isolated focal dystonia in Ireland. Eur J Neurol. 2017 Jan;24(1):73-81. https://doi.org/10.1111/ene.13133

13. Lin PT, Hallett M. The pathophysiology of focal hand dystonia. J Hand Ther. 2009 Apr-Jun;22(2):109-13. https://doi.org/10.1016/j.jht.2008.10.008

14. Chuang C, Fahn S, Frucht SJ. The natural history and treatment of acquired hemidystonia: report of 33 cases and review of the literature. J Neurol Neurosurg Psychiatry. 2002 Jan;72(1):59-67. https://doi.org/10.1136/jnnp.72.1.59

15. Ramos VF, Karp BI, Hallett M. Tricks in dystonia: ordering the complexity. J Neurol Neurosurg Psychiatry. 2014 Sep;85(9):987-93. https://doi.org/10.1136/jnnp-2013-306971

16. Loyola DP, Camargos S, Maia D, Cardoso F. Sensory tricks in focal dystonia and hemifacial spasm. Eur J Neurol. 2013 Apr;20(4):704-7. https://doi.org/10.1111/ene.12054

17. Camargo $\mathrm{CH}$, Camargos ST, Cardoso FE, Teive HA. The genetics of the dystonias - a review based on the new classification of the dystonias. ArqNeuropsiquiatr. 2015 Apr;73(4):350-8. https://doi.org/10.1590/0004-282X20150030

18. Rieder CR. Genetic of dystonias according the new classification. ArqNeuropsiquiatr. 2015 Apr;73(4):281-2. https://doi.org/10.1590/0004-282X2015005 